\title{
Rüdiger Wolfrum and Nele Matz, Conflicts in International Environmental Law
}

Springer Verlag, Berlin, 2003, 213 pp, Hardback, ISBN-10: 3-54040520-8

\section{Sebastian Oberthür and Thomas Gehring, Eds., Institutional Interaction in Global Environmental Governance. Synergy and Conflict among International and EU Policies}

The MIT Press, Cambridge Massachusetts, 2006, 424 pp, Paperback, ISBN-10: 0-262-65110-6

\section{Harro van Asselt}

Received: 17 January 2007/Accepted: 9 March 2007/Published online: 16 May 2007

(C) Springer Science+Business Media B.V. 2007

\section{Introduction}

Over the last 2 decades, we have witnessed a true proliferation of treaties and other international agreements aimed at regulating the environment. The issue coverage of the different treaties in question frequently overlaps with each other-sometimes to a large extent-and interactions between treaties may have consequences for their effectiveness. This phenomenon, which has been described as 'treaty congestion' (Brown-Weiss 1993, 679), poses a significant challenge to both practitioners and academics as different international norms may have a bearing on a particular situation. This development has not gone unnoticed by scholars in the field of political science and international law, and has led to a variety of research projects and publications on interactions between international environmental regimes (see, for example, Young 1996, 2002; Chambers 1998; Rosendal 2001; Stokke 2001; Linnér 2006). This growing body of research, on the one hand, represents a diversity of empirical case studies in which different international environmental agreements interact with each other. On the other hand, there has been some progress on theoretical approaches to understanding these interactions. However, what is missing until now in all of these studies is a link with studies conducted to address overlaps from an international law perspective. This essay will make a first, modest attempt to establish such a link.

H. van Asselt ( $₫)$

Department of Environmental Policy Analysis, Institute for Environmental Studies, Vrije Universiteit, Amsterdam, The Netherlands e-mail: harro.van.asselt@ivm.vu.nl 
In order to do so, this review essay discusses two recent and important contributions on interactions between international environmental agreements, which differ somewhat in their approach of the subject. The first book by Rüdiger Wolfrum and Nele Matz, Conflicts in International Environmental Law, specifically takes an international (environmental) law approach, focusing on conflicts between international environmental treaties. The second book, Institutional Interaction in Global Environmental Governance, edited by Sebastian Oberthür and Thomas Gehring, seeks to understand what causes international environmental institutions to interact and examines the subsequent effects of these interactions. This essay aims to show that these books have more in common than one may expect at first sight, and that the different disciplines could contribute in their own way to understanding and dealing with interactions in international environmental governance.

The essay first discusses the book of Wolfrum and Matz, and shows the options for, and limitations of international law to address interactions in international environmental governance. It then discusses how Oberthür and Gehring address the issue, showing to what extent this complements international law. Finally, it draws some conclusions.

\section{International law: how to deal with conflicts between environmental treaties?}

As the title of their book reveals, Wolfrum and Matz are primarily interested in conflicts that occur or may occur between different international environmental agreements. As Wolfrum and Matz view the problem: "most treaties exist parallel to one another and are further developed without the benefit of consideration being given to potential conflicts with other agreements either during their negotiation or at a later stage of their existence" (p. 2). They argue that these conflicts are based on functional interdependencies related to natural systems. To this, I would add that besides these ecological interdependencies, the complex nature of socio-economic systems forms an important underlying reason for conflicts in international environmental law, especially when considering conflicts between treaties concerning different issue areas, such as climate change and international trade.

In the first part of the book, Wolfrum and Matz provide some conceptual clarification with regard to the definition of 'conflict' in international environmental law. Indirectly, they show the limits of other definitions of 'conflict' used in international law. For example, Pauwelyn $(2003,5-8)$ takes a rather narrow approach to the concept of 'conflict of norms', dealing only with conflicts of legally binding norms (which can consist of obligations and rights) in international law. However, Wolfrum and Matz (p. 6) point out that, especially in international environmental law, this narrow construction of conflicts does not cover all the divergences and inconsistencies between treaties that may have negative effects.

The second part of the book provides numerous empirical examples of potential or actual cases of conflict between international treaties related to the environment, covering topics such as law of the sea, biodiversity and nature conservation, desertification, climate change, and (hazardous) waste. A few of these examples are highlighted here. In the case of the 1982 United Nations Convention on the Law of the Sea (UNCLOS) and the 1992 Convention on Biological Diversity (CBD) there is no outright clash between the agreements in terms of their provisions, but their approaches differ fundamentally (the CBD's ecosystem approach vs. UNCLOS' exploitation approach). This only emphasizes the point made above that a restrictive definition of conflict will not always be sufficient to cover 
incompatibilities between agreements. The book also examines the often-quoted conflict between the CBD and the 1997 Kyoto Protocol on climate change (Pontecorvo 1999; Jacquemont and Caparrós, 2002). One of the main worries here is that the rules established under the Kyoto Protocol enable projects that result in destructive large-scale, monoculture plantations, rather than providing protection for existing old-growth forests, and hence are contrary to the objectives of the CBD. The authors point out that the inconsistencies between the agreements are mainly caused by a lack of incentives to promote mutually supportive implementation of both agreements (p. 92). What Wolfrum and Matz do not address explicitly, but what becomes clear is that the tension between the CBD and the Kyoto Protocol is also a good example of how conflicts are not caused by the treaties themselves, but originate from subsequent rule development through decision-making by treaty bodies (such as the Conferences of Parties-COPs). The conflict between the climate and biodiversity treaties only became apparent through decisions taken by the climate COP on the modalities and procedures of its Clean Development Mechanism, as contained in the 2001 Marrakech Accords. This is a significant development, as the conflict resolution tools of international law do not provide a straightforward solution for this situation-as becomes clear further on in the book.

After giving a range of examples of interactions between international environmental treaties, Wolfrum and Matz come to the main part of their book, and address the question of how the international community can deal with conflicts. This part starts with a systematic overview of the tools for conflict resolution offered by international law. First, international law offers possibilities of addressing conflicts ex ante, through the use of socalled conflict clauses, which regulate the relation between different treaties. However, as Wolfrum and Matz show, their usefulness has been rather limited. They then turn to the options offered by the law of treaties to address conflicts that already exist. In particular, they examine to what extent the Vienna Convention on the Law of Treaties can be of assistance in resolving conflicts between environmental treaties. However, their conclusion is sobering and points to the limits of international law, as their analysis "reveals that the law of treaties can only partially be employed as a tool to solve conflicts between treaties", (p. 158). A similar conclusion was drawn in a recent article on the law of treaties by Borgen $(2005,605)$, who observes that " $[\mathrm{w}]$ hen instances of treaty conflicts are mentioned it is usually by academics or other observers. Further, when such conflicts do attract the attention of decisionmakers, they tend to be resolved in ad hoc political bargains rather than by an application of blackletter principles'. In other words, in dealing with conflicts, politics inevitably come into play. Ending on a more positive note, however, Wolfrum and Matz argue that international law still offers some avenues to address conflicts between treaties, including a more careful and clear drafting of conflict clauses, and through treaty interpretation.

Yet given the limits of the international law in addressing conflicts, it is not surprising that the authors move on to discuss options outside of the law of treaties to improve coordination between international environmental agreements and enhance cooperation between the relevant actors in international environmental governance. These relevant actors not only include the traditional subjects of international law, States and international organizations, but also other actors such as treaty bodies (including COPs and Secretariats) and non-governmental organizations (NGOs). Cooperation between these actors can take many shapes and forms, from information exchange to concluding Memoranda of Understanding or Cooperation, to the establishment of partnerships between treaty bodies. 
The authors also touch upon the role of UN institutions, such as the United Nations Environment Programme (UNEP) and the Commission on Sustainable Development, in coordinating the interactions between different international environmental agreements.

Wolfrum and Matz conclude with some general recommendations for dealing with conflicts in international environmental law. They argue first that it may be useful to list all potential interactions before the start of negotiations of a new environmental agreement. Such a recommendation is sensible, although it should be noted that the number of new environmental treaties is becoming smaller. What is more important is not only the listing of potential interactions with other treaties that needs to take place, but also conceiving of strategies of how to deal with those interactions. A second recommendation is that treaty bodies (notably COPs) may play an important role in dealing with conflicts and ensuring harmonization of the different norms. However, as the authors warn, it is possible that the conflict is then dealt with from the perspective of one of the treaties in question only. Third, a reform of the law of treaties is called for "so as to keep up with the general tendency for more dynamic and interactive structures in international law"' (p. 211). This conclusion, as well as some other parts of the book, displays a general lack of satisfaction with the ability of international law to deal with dynamic developments in the field of the environment, where new scientific insights and political changes lead to a desire to quickly adapt to new circumstances. Finally, the authors put forward some suggestions with regard to the reform of international environmental governance, and the role of UNEP in particular. However, they do not provide an in-depth suggestion on how this reform should take place-although it can be argued that such a discussion is outside the scope of the book.

All in all, the book by Wolfrum and Matz provides a timely and comprehensive introduction to the problem of conflicts between international environmental agreements, and the ways of dealing with them. Whereas international legal literature is primarily occupied with conflicts between treaties outside of the environmental realm (most notably trade and human rights law; see for example Pauwelyn, 2003; ILC, 2006), the authors show that international environmental law merits attention in this debate. Furthermore, they point to the limits of international law in dealing with conflicts in international environmental law, and show that it is necessary to consider strategies for coordination and cooperation between international environmental agreements.

\section{Political science: causes and effects of institutional interactions}

The second book reviewed here deals with the same phenomenon, but takes a very different starting point. As Gehring and Oberthür explain in their introduction, they aim to " advance our knowledge about institutional interaction by focusing on the causal influence of governance institutions on each others' normative development and performance', (p. 5). Hence, they seek to explain what causes interactions between institutions to take place. They define institutional interaction as the "causal relationship between two institutions, with one of these institutions ('the source institution') exerting influence on the other ('the target institution')"' (p. 6).

Before continuing, a few differences in approaches of the books should be made explicit. First, while Oberthür and Gehring focus on international institutions, Wolfrum and Matz examine only treaties. This means that Oberthür and Gehring also address interactions between for example international organizations and treaty-based regimes, 
such as interactions between the International Maritime Organization and the Kyoto Protocol. Second, Oberthür and Gehring include in their analysis interactions between environmental and non-environmental institutions, such as interactions between the Cartagena Protocol on Biosafety and the World Trade Organization (WTO), as well as interactions with and among European Union legal instruments, whereas Wolfrum and Matz do not deal with these interactions. Last, but not least, Oberthür and Gehring are not only interested in negative outcomes of interactions ('conflicts' or 'disruptions'), but also try to explain how positive interactions ('synergies') come to pass. In fact, one of their main findings is that the majority of cases examined in their book lead to synergy, a conclusion that sheds some doubt to the heavy preoccupation with conflicts of many policy-makers and academics.

In a conceptual chapter, Oberthür and Gehring provide a classification of the causal mechanisms of institutional interaction, in which they distinguish four types of interaction: (1) Cognitive interaction, meaning that one institution is influenced by information or ideas stemming from another institution; (2) Interaction through commitment, or the influence of the commitments entered into under one institution on another institution; (3) Behavioral interaction, referring to behavioral effects triggered by one institution which has an influence on the effectiveness of another; and (4) Impact-level interaction, where the ultimate targets of institutions interact. The last type of interaction is not further discussed in their book, as its analysis would be too complex.

The largest part of the book consists of an impressive number of empirical case studies. In each case study, one institution is chosen as the centre of interactions. The institutions covered in the book include highly relevant ones, such as the climate change regime, the Convention on Biological Diversity, the Convention on International Trade in Endangered Species (CITES), and the WTO at the international level, and the Water Framework, Integrated Pollution Prevention and Control (IPPC), Habitats, and Air Quality Framework Directives at the EU level. The chapters first give a useful, non-exhaustive overview of the main interactions in which the central institution is involved. This is followed by an indepth analysis of one or more interactions, in which the causal mechanism of the interactions is identified and explained. Furthermore, the various contributions in the book examine to what extent there has been a policy response to the interaction. Obviously, not all interactions between all institutions can be examined, but the book provides an overview of 163 cases of interaction in an Appendix that gives information on, among others, whether these cases are conflicting or synergetic, and to what type of interaction they belong. The case study chapters are written by authors that have extensive experience in the empirical fields covered. However, the use of the common conceptual framework as developed by Oberthür and Gehring ensures that the book remains consistent throughout.

Some interesting findings emerge from the case studies directly. Rosendal's chapter on the CBD points out how the interaction between the WTO Agreement on Trade-Related Intellectual Property Rights (TRIPS) and the CBD has taken the form of an "arms race", (p. 92), in which the effectiveness of both agreements is affected. In determining the aggregate outcome of the interaction, the means available to the different institutions then come into play, as "the TRIPS Agreement may be better equipped than the CBD" (p. 94). The chapter by Skjærseth addresses how 'soft law' interacts with hard law with positive outcomes in the case of pollution of the Northeast Atlantic. The role of soft law in furthering the development of hard law is also underlined by Wettestad in a case study on the EU Air Quality Framework Directive. It is unfortunate that the role of soft law is not further discussed systematically, as especially in the area of international environmental governance, soft law instruments, such as political declarations and non-binding 
agreements, play an important role in shaping binding commitments and subsequently altering behavior. The chapter on CITES by Lanchbery shows how interactions could be synergetic at the level of outputs (decisions by COPs, etc.), but that this does not always mean that the impact level effectiveness (i.e. effects "on the ground") is enhanced. Farmer, in his case study on a range of EU Directives, comes to the counterintuitive conclusion that in some cases, "double work" may be desired. In this case, "double work" refers to the existence of double regulation for the same situation, requiring more effort for implementing and enforcing actors. Although from an efficiency point of view this may sound like nonsense, Farmer points out that in some cases it is beneficial "to resort to a safety-net approach', (p. 228).

In a thoroughly written final chapter, Gehring and Oberthür compare their empirical cases and come to some tentative conclusions. They indicate on what basis the different interactions can be distinguished: the type of effect produced; policy fields covered; intentionality; objectives, membership and means of governance of the institutions; the kind of policy response; and room for further improvement. As indicated above, they find that cases of synergy are more frequent than cases of disruption. However, they add that this does not mean "that everything is all right with international and EU environmental governance" (p. 318). Gehring and Oberthür further point out that the policy responses have been more frequent in cases of disruption compared to cases of synergy.

One of the issues that the book does not address is to what extent interactions result in synergies or disruption/conflict. Admittedly, throughout the case studies, authors provide indications of the significance of the outcome of the interaction, but it is difficult for the reader to establish which interactions require immediate attention. Related to this is the slippery slope of determining the impacts on effectiveness, to which the editors explicitly relate their work. Oberthür and Gehring explain early in the book how they seek to understand the causal mechanisms of interactions. The underlying thought is that these mechanisms end in some kind of impact on the effectiveness of an institution. However, the determination of effectiveness raises a number of questions: What is the ultimate target of an institution? Is it possible to even know an institution's ultimate target (Mehling 2002)? If so, how can we measure progress towards such a target? And how can we attribute this progress to the interaction? These questions remain largely unanswered in this book.

Oberthür and Gehring acknowledge that the cases examined in the book are primarily cases with a straightforward causal chain, and call for research on more complex cases of interaction. They also admit that it is too difficult to point out what the effects of institutional interaction are at the impact level. Finally, they concede that-even though a considerable number of cases have been examined-the empirical case studies are not representative for institutional interactions in general.

In sum, Oberthür and Gehring have made an important step forwards in increasing our understanding of the causes and effects of specific cases of institutional interactions, and convincingly show that there is still much to explore in this area.

\section{Conclusions}

Even though the books reviewed here take a rather different approach, two similarities between them should be emphasized. First, the starting point of the two books is the same: the phenomenon that in international environmental governance, there is a multitude of 
international legal instruments and a range of actors that aim to govern human-environment relations. Second, both books point to the importance of considering positive and negative interactions between those instruments and actors. Being aware that different international institutions do not operate in isolation is a first step to creating proper policy responses for dealing with conflicts and enhancing synergies. Oberthür and Gehring point out that the great potential for synergies in many cases merits attention. However, there is still the important task of addressing interactions resulting in conflicts, including through the methods outlined by Wolfrum and Matz.

Overall, both books provide valuable insights in the causes and effects of, and possible responses to, conflicts and synergies in international environmental governance. They also show that there is still much left to understand, and that it is not easy to devise strategies to deal with interactions. Nevertheless, the books show that efforts from different disciplines can contribute to such strategies.

\section{References}

Borgen, C. J. (2005). Resolving treaty conflicts. The George Washington International Law Review, 37(3), 573-648.

Brown-Weiss, E. (1993). International environmental law: Contemporary issues and the emergence of a new order. Georgetown Law Journal, 81, 675-710.

Chambers, W. B. (Ed.), (1998). Global climate governance: inter-linkages between the Kyoto protocol and other multilateral regimes. Tokyo: United Nations University Institute of Advanced Studies and Global Environment Information Centre.

ILC (2006). Fragmentation of international law: Difficulties arising from the diversification and expansion of international law. Report of the Study Group of the International Law Commission. A/CN.4/L.682 (13 April 2006). (Geneva: International Law Commission).

Jacquemont, F., \& Caparrós, A. (2002). The convention on biological diversity and the climate change convention 10 years after Rio: Towards a synergy of the two regimes? Review of European Community and International Environmental Law, 11(2), 139-180.

Linnér, B.-O. (2006). Authority through synergism: The roles of climate change linkages. European Environment, 16(5), 278-289.

Mehling, M. A. (2002). Betwixt Scylla and Charybdis: The concept of effectiveness in international environmental law. Finnish Yearbook of International Law, 13, 129-182.

Pauwelyn, J. (2003). Conflict of norms in public international law. How WTO law relates to other rules of international law. Cambridge, UK: Cambridge University Press.

Pontecorvo, C. M. (1999). Interdependence between global environmental regimes: The Kyoto protocol on climate change and forest protection. Zeitschrift für ausländisches öffentliches Recht und Völkerrecht, 59(3), 709-749.

Rosendal, G. K. (2001). Impacts of overlapping international regimes: the case of biodiversity. Global Governance, 7, 95-117.

Stokke, O. S. (2001). The interplay of international regimes. Putting effectiveness theory to work. FNI Report, no. 14/2001. (Lysaker, Norway: The Fridtjof Nansen Institute).

Young, O. R. (1996). Institutional linkages in international society: Polar perspectives. Global Governance, 2(1), 1-24.

Young, O. R. (2002). The institutional dimensions of environmental change. Fit, Interplay, and scale. Cambridge, MA: MIT Press. 